\title{
EFFECTS OF EARLY AND LATE CLAMPING OF UMBILICAL CORD ON HAEMOGLOBIN LEVEL OF PRETERM INFANTS AT 6 WEEKS
}

\author{
Ashish K. Gupta1, Suhail A. Naik2, Ranjit Ghuliani3 ${ }^{3}$ Mohd Irshad ${ }^{4}$
}

${ }^{1}$ Resident, Department of Paediatrics, Army Hospital Research and Referral, Delhi, India.

${ }^{2}$ Senior Resident, Department of Paediatrics, GB Pant Children Hospital, Srinagar, Kashmir, India.

3 Professor, Department of Paediatrics, Army Hospital Research and Referral, Delhi, India.

${ }_{4}^{4}$ Senior Resident, Department of Paediatrics, GB Pant Children Hospital, Srinagar, Kashmir, India.

\begin{abstract}
BACKGROUND

The potential benefits of delayed cord clamping have been identified and they include less intraventricular haemorrhage, less need for blood transfusion, improvement in the blood pressure and cerebral oxygenation in low birth weight neonates. Increasing iron stores in infants through delayed cord clamping may be particularly beneficial in resource-poor settings where severe anaemia is common. The haematological benefits of delayed cord clamping in term and preterm babies has been found by many previous studies. The different haematological parameters which have shown improvement in preterm babies were higher levels of haemoglobin and haematocrit, and subsequent reduction in frequency of blood transfusions in first 4 to 6 weeks of life.
\end{abstract}

\section{METHODS}

This non-randomized trial was conducted in the department of Obstetrics \& Gynaecology and Paediatrics at Army Hospital (Research \& Referral), Delhi Cantt. from May 2011 to Apr 2013. Premature babies born consecutively between 34 to 36 weeks \& 6 days of gestation were randomized with computer generated random number tables to delayed cord clamping (DCC) and early cord clamping (ECC) group as case \& control.

\section{RESULTS}

100 preterm neonates were included in study. Early cord clamping (ECC) was done in 50 babies and delayed cord clamping (DCC) in 50 babies. At six weeks of age haemoglobin in both DCC versus ECC group was measured. Haemoglobin levels in DCC group $(9.25 \pm 0.59 \mathrm{gm} / \mathrm{dl})$ were significantly higher than those in ECC group $(9.0 \pm 0.50 \mathrm{gm} / \mathrm{dl})(\mathrm{p}-0.018)$.

\section{CONCLUSIONS}

Delayed cord clamping is safe and beneficial in premature neonates and is recommended for practice.

HOW TO CITE THIS ARTICLE: Gupta AK, Naik SA, Ghuliani R, et al. Effects of early and late clamping of umbilical cord on haemoglobin level of preterm infants at 6 weeks. J. Evolution Med. Dent. Sci. 2019;8(13):982-987, DOI: 10.14260/jemds/2019/220

\section{BACKGROUND}

In an active management strategy, the umbilical cord is usually clamped shortly following birth of the infant. This is generally carried out in the first 30 seconds after birth, regardless of whether the cord pulsation has ceased. ${ }^{1}$ Late cord clamping, or delayed clamping, a physiological approach, involves clamping the umbilical cord when cord pulsation has ceased. However, definitions of what constitutes early and late cord clamping vary. 2,3 This placental transfusion can provide the infant with an additional $30 \%$ more blood volume and up to $60 \%$ more red blood cells. ${ }^{1}$

The amount of blood returned to the infant also depends on when the cord is clamped and at what level the infant is held (Above or below the mother's abdomen) prior to clamping. ${ }^{4}$

'Financial or Other Competing Interest': None.

Submission 29-12-2018, Peer Review 14-03-2019,

Acceptance 20-03-2019, Published 01-04-2019.

Corresponding Author:

Dr. Suhail Naik,

54 Al-Farooq Colony,

Bemina-190015,

Kashmir, India.

E-mail: suhailpediatrics@gmail.com

DOI: $10.14260 /$ jemds $/ 2019 / 220$

\section{(c) (1) $(9)$}

Early cord clamping may increase the likelihood of fetomaternal transfusion (The amount of blood that is forced back across the placental barrier into the maternal circulation), as a larger volume of blood remains in the placenta. This would have been considered a potential issue prior to the introduction of $\mathrm{Rh} \mathrm{D}$ immunoglobulin prophylaxis, since early clamping of the cord was considered to increase the risk.

The potential benefits of delayed cord clamping have been identified and they involve less intraventricular haemorrhage, less need for blood transfusion, improvement in the blood pressure and cerebral oxygenation in low birth weight neonates.5,6 Increasing iron stores in infants through delayed cord clamping may be particularly beneficial in resource-poor settings where severe anaemia is common. ${ }^{7}$ There is a concern that delayed cord clamping could result in polycythaemia and hyperbilirubinaemia. ${ }^{8}$ It is vital to keep in mind that there are some situations in which it is advisable to perform early cord clamping. ${ }^{9}$ For instance, infants with hydrops are already overloaded with fluid and may not tolerate additional volume; during foetal distress there is also a greater than normal transfer of blood from the placenta to the foetus prior to delivery; infants at risk for polycythaemia, such as infants of diabetic mothers or severely growth restricted infants, severely asphyxiated infants, and in cases where resuscitative efforts need to be initiated without delay, early cord clamping may be warranted.9,10 
The delayed cord clamping has obvious haematological benefits both in term and preterm infants as observed in many previous studies. The term infants with delayed cord clamping had higher haemoglobin, haematocrit and ferritin levels at the age of 2 months.11 Further various expert committees including World Health Organization (WHO), American Academy of Paediatrics, and one of the studies have stressed on prevention of anaemia during first six weeks of life for normal physical and cognitive development and therefore a strong reason to delay cord clamping. ${ }^{12,13,14}$

Furthermore it has been found that delayed cord clamping is associated with better pulmonary and systemic vasodilatation due to significant fall in peripheral and pulmonary vascular resistances and consequently higher blood flow to the brain, body, and intestines. ${ }^{15,16}$ In preterm infants it was associated with a better cardiopulmonary adaptation and subsequently decreased dependence on supplemental oxygen or fewer days of assisted ventilation. ${ }^{15,17,18}$

The various hematologic and hemodynamic benefits of delayed cord clamping found were increased level haemoglobin and haematocrit, improved systemic circulation and reduced need for blood transfusions in the first 4 to 6 weeks in preterm infants.15,17,18,19 The other benefits of delayed cord clamping DCC were better adaptation to immediate external environment and decreased use of supplemental oxygen or assisted ventilation for preterm infants. ${ }^{15,16}$ With the result these neonates also had at least 3 minutes increased duration of early breastfeeding as compared with early clamped infants. ${ }^{20}$ The delayed cord clamping also increases blood volume and iron stores at birth, which is very important for preventing iron deficiency anaemia during infancy. In developing countries around 50\% of infants become anaemic by 1 year of age ${ }^{21}$ and estimates in some countries well exceed this percentage. Though there are many causes of anaemia but iron deficiency is one the principal cause of anaemia in infants.

There are various concerns regarding delayed cord clamping like polycythaemia, hyper viscosity, hyperbilirubinaemia, and transient tachypnoea of the newborn.

Saigal and Usher initially raised the concern that delayed cord clamping may be a potential for neonatal polycythaemia in 1977.22 Polycythaemia which is defined as venous haematocrit level greater than $65 \%$ and has nonspecific clinical manifestations like dusky skin colour, tachypnoea, retractions, rales, cyanosis, grunting, hypotension, and hypoglycaemia, neurologic symptoms, apnoeic spells and irritability. ${ }^{22,23,24}$

Furthermore hyperbilirubinemia from delayed cord clamping in preterm infants have been found in one older study 25 but inclusion of some small for gestation age neonates was a significant confounding factor.

Transient tachypnoea of the newborn (TTN) which occurs soon after birth in some neonates and manifests by respiratory distress, tachypnoea, grunt, nasal flare, mild cyanosis and sub costal retracting. ${ }^{24}$ Though there were higher respiratory rates reported in some infants with delayed cord clamping, but overall the duration of supplemental oxygen or assisted ventilation was less in these neonates. ${ }^{26,27}$
The main objective of our trial was to identify the outcome of early and late clamping of umbilical cord on haemoglobin level of preterm infants at the age of 6 weeks.

\section{METHODS}

This non randomized trial study was conducted at department of Obstetrics \& Gynaecology and Paediatrics at Army Hospital (Research \& Referral), Delhi Cantt for a period of May 2011 to Apr 2013 in the premature babies born by normal vaginal delivery. In this trial a selective sample of more than 100 women during their second stage of labour were selected according to the following:

\section{Inclusion Criteria}

1. All the infants who were born by normal vaginal delivery (NVD) at 34 to $36 \pm 6$ weeks of gestation were assessed by obstetrician and paediatrician. The gestation age of neonates was calculated from date of last menstrual period, first trimester ultrasonography and confirmed by clinical examination as described by Ballard scale.

2. The neonates who met the following selection criteria were included in this study: birth weight $\geq 2000 \mathrm{~g}$, gestation age (34-36) \pm 6 weeks, singleton birth, vaginal delivery.

3. Written informed consent given by either parent.

\section{Exclusion Criteria}

1. Any neonates with birth asphyxia/meconium aspiration syndrome/precipitate labour/intrauterine growth retardation (IUGR)/intrauterine infection/any syndrome/congenital heart diseases/major anomaly and neonates admitted in SNCU.

2. Mother with diagnoses of placenta praevia or abruption/ bleeding/preeclampsia or eclampsia (Also in any previous pregnancies)/placental abnormalities/ hypertension/cardiomyopathies or chronic renal disease, maternal gestational diabetes, maternal drug abuse/smoking.

3. Unwilling to return for follow-up visits at the same hospital.

\section{Methodology}

The randomized control trial was conducted after necessary approval was taken from the ethical committee of hospital. More than 100 women during their second stage of labour who fulfilled all the described inclusion criteria's were randomly selected and were divided into two groups: First group ( $\mathrm{n}=50)$ : the neonates in this group had early cord clamping after birth; second group $(n=50)$ : these neonates had late cord clamping after birth. Two proforma sheets were developed collect the necessary data as follows.

\section{Maternal Proforma}

An interview questionnaire proforma sheet which contained the following two parts to collect data:

\section{Demographic Data}

Demographic data such as (Age, occupational and education level, socioeconomic status, urban -rural). 


\section{Obstetrical Data}

Obstetrical history such as (Gravida, parity, abortions, lastmenstruation period, expected date of delivery and gestational age, previous lab tests and ultra-sonography).

\section{Newborn Proforma}

A newborn proforma sheet contained the following parts.

\section{Umbilical Cord Data}

Umbilical cord clamping record sheet which consists of date, time of cord clamping after birth (Using a stopwatch).

\section{Haemoglobin Data}

1. Haemoglobin and haematocrit were estimated at six weeks of age.

2. The mothers were screened for eligibility; parents were informed about the trial and written informed consent obtained from either parent.

3. Delayed umbilical cord clamping done in fifty births selected randomly constituted the study group. Fifty early cord clamped subjects were taken as control.

4. At birth the allocated envelope was opened and staff at delivery room was told about the designed intervention. A stopwatch was also used to accurately time the cord clamping. When umbilical cord was clamped before 20 seconds, we put neonate in early cord clamping (ECC) group and when clamped at more than 20 seconds the group allotted were delayed cord clamping. Meanwhile all those neonates who were in DCC group, the team tried to hold them at a low level from introitus as much as possible without creating any extra tension on the cord while the neonate was still connected to the placental circulation. The main aim to hold the neonate around 20 to $30 \mathrm{~cm}$ below the mother's introitus during vaginal delivery was that maximum possible placental blood should get transfused in to baby. Further it was assured that no utero-tonics were administered to mother before cord clamping.

5. To avoid any untoward complication during the process of birth, the obstetricians were at full liberty to violate the described protocol whenever he or she believed that there was an urgent need for immediate clamping of umbilical cord for the wellbeing of mother and her newborn.

6. Later on, at the six weeks of age the infants from both the groups were reviewed and their haemoglobin and haematocrit levels checked. The venous blood was collected from peripheral veins using all aseptic precautions and analyses was done by Beckmen Coulter machine.

In our study around 146 preterm infants were assessed for eligibility and among them 46 infants were excluded from study. 24 neonates were excluded either due to parental refusal or technical limitation and 22 neonates were born with exclusion criteria. 50 neonates were randomised to ECC group and 50 to DCC group.

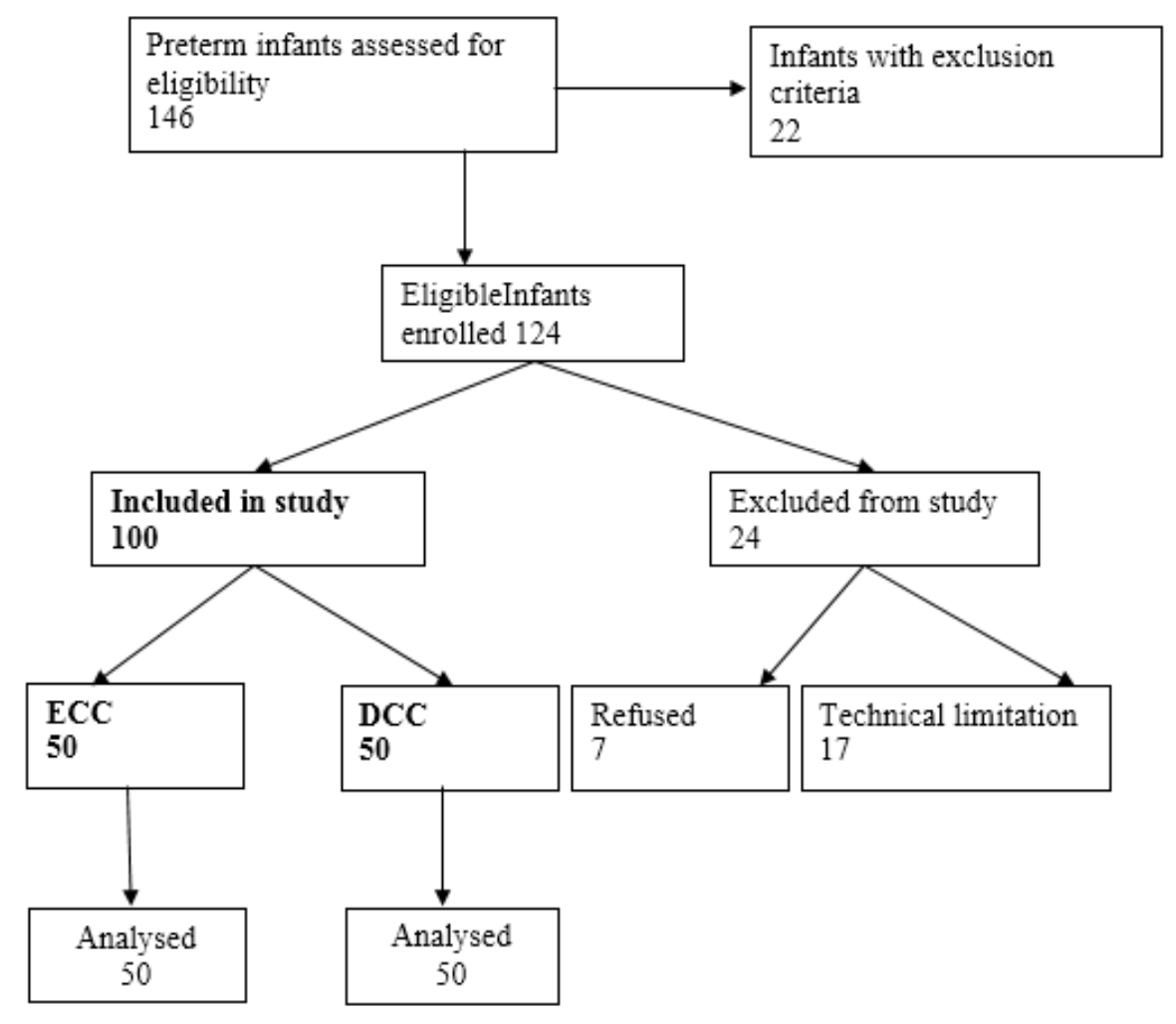




\section{Statistical Analysis}

Data collected was entered in MS excel and analysed using SPSS version 15 . The descriptive statistical measures like, mean and standard deviation were applied. Independent

sample $t$ test was applied to find out the difference in continuous variables between two groups. The differences were interpreted statistically significant at $\mathrm{P}<0.05$.

\section{RESULTS}

\begin{tabular}{|c|c|c|c|}
\hline $\begin{array}{c}\text { Maternal } \\
\text { Characteristics }\end{array}$ & $\begin{array}{c}\mathrm{ECC} \\
\mathrm{N}=50\end{array}$ & $\begin{array}{c}\mathrm{DCC} \\
\mathrm{N}=\mathbf{5 0}\end{array}$ & p-Value \\
\hline Maternal Age & $25 \pm 5$ & $26 \pm 4$ & 0.082 \\
\hline Parity & $1.8 \pm 4$ & $1.6 \pm 1$ & 0.084 \\
\hline Maternal Haemoglobin & $10.6 \pm 1.1$ & $10.8 \pm 1.4$ & 0.082 \\
\hline \multicolumn{4}{|c|}{$\begin{array}{c}\text { Table 1. Shows the Demographics Characteristics of } \\
\text { Mothers Enrolled in Study }\end{array}$} \\
\hline
\end{tabular}

The demographic and haemoglobin variables between mothers in the ICC and DCC groups were almost similar.

\begin{tabular}{|c|c|c|c|}
\hline Parameter & ECC & DCC & p \\
\hline Birth Weight & $2.5 \pm 0.30$ & $2.6 \pm 0.25$ & 0.86 \\
\hline Gestational Age & $34 \pm 2.4$ & $34 \pm 2.2$ & 0.79 \\
\hline Length & $47.6 \pm 2.1$ & $47.5 \pm 2.8$ & 0.88 \\
\hline OFC & $32.2 \pm 2.8$ & $31.9 \pm 29$ & 0.85 \\
\hline APGAR 1 Minute & 8 & 9 & 0.93 \\
\hline APGAR at 5 Minutes & 9 & 10 & 0.84 \\
\hline Mean Peak Bilirubin & $12.3 \pm 2.8$ & $13 \pm 2.5$ & 0.88 \\
\hline \multicolumn{4}{|c|}{ Table 2. Shows Different Clinical and Laboratory } \\
\hline \multicolumn{4}{|c|}{ P > 0.05 was considered of Neonates } \\
\hline
\end{tabular}

The table shows the infant characteristics like birth weight, gestational age, length, Occipito-frontal circumference and Apgar scores were similar between the two groups.

\begin{tabular}{|c|c|c|}
\hline Morbidity & ECC & DCC \\
\hline Polycythaemia & 0 & 1 \\
\hline IVH & 1 & 0 \\
\hline Sepsis & 0 & 0 \\
\hline Jaundice & 4 & 9 \\
\hline Exchange Transfusion & 0 & 0 \\
\hline Blood Transfusion & 4 & 2 \\
\hline Feeding Problems & 7 & 3 \\
\hline Patent Ductus Arteriosus & 1 & 0 \\
\hline \multicolumn{3}{|l|}{ Respiratory Distress Syndrome } \\
\hline Apnoea & 1 & 1 \\
\hline Hypoglycaemia & 3 & 2 \\
\hline Transient Tachypnoea of Newborn & 1 & 2 \\
\hline Necrotizing Enterocolitis & 1 & 1 \\
\hline \multicolumn{3}{|c|}{$\begin{array}{l}\text { Table 3. Shows Frequency of Neonatal Complications } \\
\text { During the Infant's Stay in The Hospital in Both Groups }\end{array}$} \\
\hline
\end{tabular}

There was no significant difference in neonatal morbidity in between two groups.

\begin{tabular}{|c|c|c|c|}
\hline & ECC & DCC & p-Value \\
\hline${ }^{*} \mathrm{Hb}_{1}$ at Day 1 & $17.6 \pm 2.5$ & $18.5 \pm 3.0$ & 0.055 \\
\hline${ }^{*} \mathrm{Hct}_{1}$ at Day 1 & $52.8 \pm 5.2$ & $55.5 \pm 5.4$ & 0.052 \\
\hline${ }^{\text {} \mathrm{Hb}_{2} \text { at } 6 \text { Weeks }}$ & $9.0 \pm 0.50$ & $9.25 \pm 0.59$ & 0.018 \\
\hline${ }^{\text {\#Hct }}$ 6 Weeks & $27.2 \pm 2.6$ & $27.75 \pm 2.58$ & 0.032 \\
\hline
\end{tabular}

Table 4. Shows Comparison of Haemoglobin at 6 Weeks of Age in Both DCC Versus ECC Group. Haemoglobin Levels in DCC Group $(9.25 \pm 0.59 \mathrm{gm} / \mathrm{dl})$ Were More Than Those in ECC Group $(9.0 \pm 0.50 \mathrm{gm} / \mathrm{dl})(\mathrm{p}-0.018)$

*Haemoglobin and haematocrit at day 1 of age. \#Haemoglobin and haematocrit at 6 weeks of age $P$ value $<0.05$ significant

There was a total of 124 deliveries in the specified gestational age group during the study period. Of these, 100 eligible infants were randomized into 2 groups of 50 each. 24 babies were excluded from the study due to technical limitations or parental refusal.

The mean birth weight was $2513 \pm 300$ grams and $2643 \pm$ 256 grams in the ECC and DCC groups respectively. Their mean gestational age was $34.1 \pm 2.7$ and $34.0 \pm 2.6$ respectively. Of the total study population 48 were females and 52 males. The two groups were comparable with regard to all maternal and neonatal characteristics as shown in tables 1 and 2 .

The haemoglobin and haematocrit on follow up at $6 \mathrm{wk}$. were higher in DCC group when compared to ECC group (Table 4). The mean haemoglobin and haematocrit on day 1 of life in DCC group was higher than in the ECC group but difference was not statistically significant. However, neonates in the DCC group had higher level of serum total bilirubin than ECC group and that difference was not statistically significant. At the age of 6 weeks there was drop in haemoglobin and haematocrit levels in both ECC and DCC groups, but difference was statistically significant. Therefore, this study found out that DCC compared with ECC was associated with higher haemoglobin values at 6 weeks of life, thus giving a hemodynamic advantage to the preterm neonate during the period of anaemia of prematurity (AOP). This directly translates to lesser incidence of symptoms with lesser need of transfusions though this was not significantly proved.

\section{DISCUSSION}

Our study confirms that DCC is a quite feasible and safe intervention. We found that DCC as compared to ECC was associated with higher level of haemoglobin values at 6 weeks of life, thus giving a much-desired advantage to preterm neonates. Further this directly translates to lesser incidence of symptoms and lesser need for top-up blood transfusions though this was not significantly proved. Meanwhile neonatal hyperbilirubinemia might be a serious concern in premature neonates with delayed cord clamping, ${ }^{25}$ and in our study we also observed a trend of higher bilirubin levels in DCC group, but this difference was not statistically significant. There was no difference in need of extra phototherapy among these two groups. Our findings were consistent with findings of various other studies who have also found that there is no increased risk of hyperbilirubinemia in neonates with delayed cord clamping.5,17, and 28,9,12,29 Further no neonate needed exchange transfusion in highly reassuring that intervention is quite safe 
and not associated with pathological rise in serum bilirubin level.

Our study revealed that the DCC was not associated with any increased risk for significant polycythaemia and this finding was consistent with study done by Kinmond et al. ${ }^{28}$ In our study among all the neonates, only one had a haematocrit $>65 \%$ in the DCC group. But the neonate was asymptomatic and didn't need any intervention. Furthermore, we did not find any significant difference in overall neonatal morbidity in both groups. There are some studies that have found an improved respiratory status and function in neonates with delayed cord clamping which was reflected by improved firstday oxygen saturation $\left(\mathrm{SPO}_{2}\right)$ and median duration of supplemental oxygen required by these neonates. ${ }^{28,30}$

As for as short-term neurological morbidity was considered we found no difference between ECC and DCC group. We had a one neonate in ECC group who had developed intraventricular haemorrhage (IVH) and it does not have any statistical significance. These findings of our study were consistent with many studies done in past. 5,17,19,28 It is important to mention here that Hofmeyr et $\mathrm{al}^{31}$ in their study have reported a decrease in IVH in neonates with delayed cord clamping DCC. But no other study has confirmed their finding. Furthermore recently, Mercer et $\mathrm{al}^{32}$ in their study have found a decreased incidence of IVH in preterm neonates with DCC, but this difference in IVH between two groups was not statistically significant.

\section{Limitation of the Study}

Many events which occur during birth process may confound the results of research. There are various other birth-related factors in addition to the timing of cord clamping which can significantly determine volume of placental transfusion to neonate during birth process and include the level at which the neonate is held below introitus; intensity and duration of uterine contractions during the third stage of labour; and dose, concentration and duration of oxytocin infusion used.

The present sample size was not adequate to derive conclusive evidences on effect of timing of cord clamping on early neonatal morbidities. Also, long term developmental outcomes have not been determined.

\section{CONCLUSIONS}

1. In a preterm neonate, DCC leads to increased Hb levels compared to ECC at 6 weeks of age. This translates to a hemodynamic advantage during the period of AOP.

2. This study also showed improved APGAR scores of neonates in whom DCC was done.

3. The clinical profile of neonates with delayed clamping of cord is also better with less perceived need for blood transfusion.

4. The incidence of hyperbilirubinemia requiring phototherapy was increased in DCC group. No exchange transfusion was required.

5. There was no significant increase in the number of neonates with polycythaemia in the DCC group.

6. No beneficial or detrimental effect on the incidence of IVH was noted in the study group.

\section{Recommendation}

Delayed cord clamping is a simple yet effective intervention that provides benefits of raised haematocrit and haemoglobin levels at 6 weeks of age. However, larger studies with long term follow up for neuro-developmental outcomes are required before firm recommendations can be made.

\section{REFERENCES}

[1] McDonald S. Physiology and management of the third stage of labour. In: Fraser D, Cooper M, eds. Myles textbook for midwives. $14^{\text {th }}$ edn. Edinburgh: Churchill Livingstone 2003.

[2] Ladipo OA. Management of third stage of labour, with particular reference to reduction of feto-maternal transfusion. British Medical Journal 1972;1(5802):721-3.

[3] Prendiville W, Elbourne D. Care during the third stage of labour. In: Chalmers I, Enkin M, Keirse MJNC, eds. Effective care in pregnancy and childbirth. Oxford: Oxford University Press 1989: p. 1145-69.

[4] Yao AC, Lind J. Placental transfusion. American Journal of Diseases of Children 1974;127(1):128-41.

[5] Mercer JS, McGrath MM, Hensman A, et al. Immediate cord clamping in infants born between 24 \& 32 weeks: a pilot randomized controlled trial. Journal of Perinatology 2003;23(6):466-72.

[6] Baezinger 0, Stolkin F, Keel M, et al. The influence of the timing of cord clamping on postnatal cerebral oxygenation in preterm neonates: a randomized, controlled trial. Pediatrics 2007;119(3):455-9.

[7] McDonald S. Management of the third stage of labor. Journal of Midwifery and Women's Health 2007;52(3):254-61.

[8] Ultee CA, Van der Deure J, Swart J, et al. Delayed cord clamping in preterm infants at 34-36 weeks' gestation: a randomised controlled trial. Archives of Disease in Childhood Fetal and Neonatal Edition 2008;93(1):F20F3.

[9] Blackburn ST. Maternal, fetal \& neonatal physiology: a clinical perspective. $3^{\text {rd }}$ edn. Missouri: Saunders Elsevier 2007: p. 247-8.

[10] Rabe H, Reynolds G, Diaz-Rossello J. Early versus delayed umbilical cord clamping in preterm infants. Cochrane Database Systematic Review 2004;(4):CD003248.

[11] Geethanath RM, Ramji S, Thirupuram S, et al. Effect of timing of cord clamping on the iron status of infants at 3 months. Ind Pediatr 1997;34(2):103-6.

[12] World Health Organization. Care in normal birth: report of the technical working group meeting on normal birth. Geneva: WHO, Maternal Health and Safe Motherhood Program, 1996.

[13] American Academy of Pediatrics Work Group on Cord Blood Banking. Cord blood banking for potential future transplantation: subject review. Pediatrics 1999;104(1 Pt 1):116-8.

[14] Pisacane A. Neonatal prevention of iron deficiency. BMJ 1996;312(7024):136-7.

[15] Nelle M, Fischer S, Conze S, et al. Effects of later cord clamping on circulation in prematures. Pediatr Res 1998;44:420.

[16] Nelle M, Zilow EP, Bastert G, et al. Effect of Leboyer childbirth on cardiac output, cerebral and gastrointestinal blood flow velocities in full term neonates. Am J Perinatol 1995;12(3):212-6. 
[17] Ibrahim HM, Krouskop RW, Lewis DF, et al. Placental transfusion: umbilical cord clamping and preterm infants. J Perinatol 2000;20(6):351-4.

[18] Rabe H, Wacker A, Hulskamp G, et al. Late cord clamping benefits extrauterine adaptation. Pediatr Res 1998;44:454.

[19] Rabe H, Wacker A, Hulskamp G, et al. A randomised controlled trial of delayed cord clamping in very low birth weight preterm infants. Eur J Pediatr 2000;159(10):775-7.

[20] Oxford Midwives Research Group. A study of the relationship between the delivery to cord clamping interval and the time of cord separation. Midwifery 1991;7(4):167-76.

[21] Johnston JL, Gillespie S. Expert consultation on anaemia: determinants and interventions: proceedings of a conference held Sept. 16-17, 1997, Ottawa, Canada. The Micronutrient Initiative 1998.

[22] Saigal S, Usher RH. Symptomatic neonatal plethora. Biol Neonate 1977;32(1-2):62-72.

[23] Polin R, Fox W. Fetal and neonatal physiology. $2^{\text {nd }}$ edn. Philadelphia: W B Saunders 1998.

[24] Fanaroff A, Martin R. Neonatal-perinatal medicine: diseases of the fetus and infant. $6^{\text {th }}$ edn. Boston: Mosby 1997.

[25] Yao AC, Lind J. Effect of gravity on placental transfusion. Lancet 1969;2(7619):505-8.
[26] Oh W, Lind J, Gessner IH. The circulatory and respiratory adaptation to early and late cord clamping in newborn infants. Acta Paediatr Scand 1966;55(1):17-25

[27] Oh W, Wallgren G, Hanson JS, et al. The effects of placental transfusion on respiratory mechanics of normal term newborn infants. Pediatrics 1967;40(1):6-12.

[28] Kinmond S, Aitchinson TC, Holland BM, et al. Umbilical cord clamping and preterm infants: a randomized trial. BMJ 1993;306(6871):172-5.

[29] Wardrop CA, Holland BM. The roles and vital importance of placental blood to the newborn infant. J Perinat Med 1995;23(1-2):139-43.

[30] Usher RH, Saigal S, O'Neil A, et al. Estimation of red blood cell volume in premature infants with and without respiratory distress syndrome. Biol Neonate 1975;26(3-4):241-8.

[31] Hofmeyr GJ, Bolton KD, Bowen DC, et al. Periventricular/ intraventricular hemorrhage and umbilical cord clamping. Findings and hypothesis. S Afr Med J 1988;73(2):104-6.

[32] Mercer JS, Vohr BR, McGrath MM, et al. Delayed cord clamping in very preterm infants reduces the incidence of intraventricular hemorrhage and lateonset sepsis: a randomized, controlled trial. Pediatrics 2006;117(4):1235-42. 